\title{
Niche shifts lead to hybridization between two Amazona parrot sister-species introduced to Southern California
}

James M. Maley' ${ }^{1}$, Rowdy J. Freeland ${ }^{1}$, Devon A. DeRaad ${ }^{1}$, Amanda J. Zellmer ${ }^{2}$, Margaret E. Schedl ${ }^{1}$, Brooke Durham ${ }^{3}$, Whitney L.E. Tsai ${ }^{1}$, Ryan S. Terrill ${ }^{1}$, Siddharth Sannapareddy ${ }^{1}$, Kimball L. Garrett ${ }^{4}$ and John E. McCormack ${ }^{* 1,2}$

This paper has been withdrawn by the authors while evaluating reviewer concerns about interpretation of the genomic data and due to errors found by the authors in the scoring of photos. Therefore, the authors do not wish this work to be cited as a reference for the project. If you have any questions, please contact the corresponding author. 